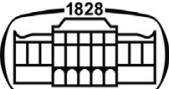

AKADÉMIAI KIADÓ

\title{
Passive immunization: Paradoxical and traditional method for new pandemic challenge COVID-19
}

\section{Acta Microbiologica et Immunologica Hungarica}

67 (2020) 2, 87-90

DOI:

$10.1556 / 030.2020 .01199$

(c) 2020 Akadémiai Kiadó, Budapest

\section{ORIGINAL ARTICLE}

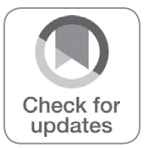

\section{AMINA IFTIKHAR, FAIZA JABEEN* ${ }^{*}$, MALEEHA MANZOOR, TAHIRA YOUNIS and MUSSARAT SHAHEEN}

Department of Zoology, Government College University Faisalabad, Faisalabad, Pakistan

Received: April 21, 2020 • Accepted: May 04, 2020

Published online: July 03, 2020

\section{ABSTRACT}

World has been suffering from pandemic caused by mysterious Coronavirus. The novel member of Coronaviridae causing COVID-19 disease is named as SARS-Cov-2. Its first case was reported in China by the end of 2019, but its exponential spread has wrapped entire globe, suspended and is penalizing mankind. A retrospective meta-analysis study showed that outbreaks of Middle East Respiratory Syndrome (MERS) and SARS-Cov-1 (Coronaviridae), influenza infection H1N1 and West-African Ebola caused lower mortality than this new pandemic COVID-19. Virus has appeared as a new human pathogen so to counter COVID-19 no specific vaccine, monoclonal antibodies have been manufactured till day. The outbreak of novel Coronavirus is treated with antimicrobial drugs but they have their own mild side effects. But the drastic spread of COVID-19 compels us also to use other ways to counter pandemic. Thus, passive immunization can be opted to hold back this mysterious virus. Passive immunization has been in use since early 20th century and showed its effectiveness against all previous infectious outbreaks including MERS and SARS-Cov-1 members of Coronaviridae. The review argues that convalescent plasma is an explicit option for containment of COVID-19 disease.

\section{KEYWORDS}

COVID-19, Corona, virus, pandemic, passive immunity

\section{INTRODUCTION}

COVID-19 pandemic finds its roots in Wuhan (China) in December 2019, a peculiar illness causing pneumonia. Such mysterious pneumonia cases were investigated to be caused by a novel virus (2019-nCoV) of family Coronaviridae [1]. Severe Acute Respiratory Syndrome (SARS) [2] and Middle East Respiratory Syndrome (MERS) viruses [3] are also members of this family. They show a few similarities but Coronavirus has alien characteristics that make it different from other members of this family, yet to identify.

Coronaviridae family has been pivotal in virologist's research since epidemics outbreak by SARS and MERS [4]. They gave significant setback to the economies of epicenters and raised death toll at globe. By the report of WHO, in 2003 the outbreak of SARS caused 774 deaths and infected 8,089 people worldwide [5]. The outbreak of MERS caused 862 deaths and 2,506 infected patients raised from 2012 to 2020 by report of WHO. But regrettably the number of infectious patients and death toll by new pandemic is far beyond the epidemics of SARS and MERS. The most challenging task to cope with pandemic is the unavailability of COVID-19 vaccine in global market. The world best laboratories have been concerned in vaccine development since its outbreak in December 2019 but still no country could make its vaccine. Chloroquine [6] or traditional methods as passive immunity are practiced to treat COVID-19 patients [7]. 
Containment and quarantine of infected patients is focused in current situation. But the outbreak can be ended by the development of effective vaccine which may take time. Traditional ways can reduce mortality caused by this mystery because it cannot be afforded to raise death toll and infectious tally and halted economies worldwide. We review potential options to treat COVID-19, particularly passive immunization, with rhetoric emphasize on timeliness development of effective therapies. The purpose of view is to underscore passive immunization to combat COVID-19 a traditional way that had been used to treat SARS [8] and MERS [9].

The mode of action of Coronaviruses is to infect the upper and lower respiratory tract, but sheds viral particles in plasma. As no specific vaccine is available, the main focus is on oxygenation, ventilation and fluid management besides antimicrobial agents or passive immunization [10, 11].

Passive immunization has been in practice since late 19th century. It has become a traditional way to treat infectious diseases for which particular medicine has not been developed. This therapy has been successfully used for a number of infectious diseases with no severe side effects. The previous researchers viewed that it worked against infectious diseases with no lethal side effect on human health [12]. Use of passive immunization during the outbreak of related coronaviruses as SARS and MERS epidemics, reduced mortality rate and contained their spread and serious adverse effects had not been reported [13].

Passive immunization is used to prevent disease but not as a permanent tool to treat disease. Convalescent plasma therapy is only effective when administered in early stage of disease as sudden after onset of symptoms. Although studies showed that in case of COVID-19 it has been effective while in critical conditioned patients as reported in China $[14,15]$.

\section{PASSIVE IMMUNIZATION USE IN PAST EPIDEMICS}

The use of passive immunization for infectious diseases is not new. On the onset of 20th century passive immunization was used as an effective tool to cure epidemics such as Poliomyletitis [16], mumpus [17], measles [18] and influenza [19]. A retrospective study showed that in 1918 during influenza H1N1 outbreak, approximately 1,703 patients received convalescent sera and they had low mortality rather than those without receiving convalescent plasma therapy [20].

In 21st century the first time use of convalescent sera was against the influenza H1N1 in 2009-2010. The preparation of antibodies from convalescent serum were used to treat sever patients of influenza H1N1. The patients treated with convalescent serum showed reduction of respiratory viral burden, serum cytokine responses within few days [21]. Moreover, in 2013 outbreak of West-African Ebola was also treated with convalescent serum. Meta-analysis of studies showed that passive immunization reduced mortality by
Ebola pandemic [22]. Passive immunization has been used in America, Asia, Africa and Europe since any infectious disease outbreak.

The response of convalescent therapy was different for different viral infections, but it showed significant results and reduced mortality in all cases. Thus in this mysterious COVID-19 pandemic, passive immunization may contain spread of infection and reduce mortality as it did to confront past outbreaks.

\section{REQUIREMENTS TO DEPLOY CONVALESCENT SERUM}

The serum of patient who contracted infectious disease and recovered later, is used to treat patients who affected by same infectious disease in future [23]. The method of Passive immunization is simple but an effective tool against infectious outbreaks.

The deployment of antibody by Passive immunity to treat COVID-19 requires six conditions.

1. Donors recovered from COVID-19 and able to donate serum

2. Availability of blood banking facilities for processing of Serum donation

3. Facility of assays as Serological assays and Virological assays

4. Availability of well-equipped virology laboratory to carry out these assays

5. Preventive and therapeutic protocols to assess the efficacy of immune response

6. Regulatory compliance which requires institutional review approved by board $[8,24]$.

To carry out passive immunization, any administrating body must meet above conditions. To reduce mortality by COVID-19, above requirements be available in each area affected by COVID-19. Each of these conditions should be available in developed areas affected by COVID-19. To undertake the importance of convalescent plasma, a largest pharmaceutical company Takeda is working to develop antibody against SARS-2, taking COVID-19 convalescent plasma [7].

\section{EARLY EXPERIMENT ON PLASMA THERAPY AGAINST COVID-19}

In mid of March 2020, a report published in Journal of the American Medical Association described that in China 5 critical patients of COVID-19 recovered by passive immunization in first experiment. The age of patients ranged 3665 , including 2 females and 3 males. The critical patients were treated by receiving convalescent plasma with COVID19 specific (IgG) binding titer greater than 1:1000, the end point of dilution titer was performed enzyme-linked immunosorbent assay and along a neutralization titer 
greater than 40 . The time duration for administration of convalescent plasma was between 10 and 20 days after admission. But the concerning point is that during treatment the patients were also receiving mechanical ventilation and Methylprednisolone. Following plasma transfusion along ventilation and anti-viral agents, the body temperature of four patients normalized within 3 days. High-titer specific antibody is able to bind to SARS-CoV-2 and then neutralize the viral agents, activate potent effector mechanism as complement activation and phagocytosis [14]. The figure shows the structure of antibodies.

As the outbreak continues, more patients who survived infection will become available to serve as donors to make antisera for 2019-nCoV, and a sizeable stock of antisera could be developed to serve as a treatment for the sickest patients $[11,25]$. While transfusion medicine services should certainly pursue convalescent patient sera as an option right now for patient treatment, it is ultimately limited in its effective scope of controlling the outbreak.|

\section{RECOMMENDATION OF PASSIVE IMMUNITY}

There are above $1,150,000$ people that have been recovered from COVID-19 till the date [26]. This majority of recovered individuals can contribute as valuable source to donate their serum to confront coronavirus at large scale. A research conducted on patients in the center of pandemic outbreak Wuhan (China) treated with convalescent plasma therapy showed effectiveness of this therapy and researchers, virologists, immunologists recommended passive immunization to contest COVID-19 [27]. National biotech group of China described that 10 seriously ill patients received convalescent serum and they improved oxygenation and reduced viral load and inflammation. Moreover China has recommended the passive immunity technique to Italy and doctors from China have taken convalescent serum to Italy [28]. By the end of March Pakistan's top medical specialist Dr. Tahir Shamsi also recommended of Passive immunization in Pakistan. Many countries across the world including Turkey, France and the U.S. are holding clinical trials for plasma therapy or transfusion to fight the novel virus [29]. Owing to lack of potent vaccine and the exponential spread of Coronavirus the US Food and Drug Administration Authority (FDA) has approved the use of passive immunization [30].

New York city has established blood banks to collect and process donations from recovered patients of COVID-19 [31]. Moreover Mount Sinai Health System in New York has organized cooperation with FDA and other hospitals of USA to commence trials to determine the effectiveness of passive immunization. But these organizations have not reported any case of passive immunization with adverse effects till the date [32]. In April 2020, International Society of Blood Transfusion published a document that has been endorsed by Competent Authorities of Human Origin Expert Group (CASoHO E01718) to provide a common platform for
European Union (EU) member states aims to the donation, collection, testing, processing, storage, distribution and monitoring of convalescent plasma for treatment of COVID-19. This document has been taken into consideration by the consultation of competent authorities for blood and blood components and by the European Center for Disease Prevention and Control. This document aims to use convalescent plasma therapy across EU member states with collective collaboration [33]. Besides passive immunization a number of western and European labs are working to develop drug for COVID-19 from convalescent plasma. Recently in Japan, the drug manufacturers of Takeda Pharmaceutical Company is planning to develop a new drug by obtaining a mixture of anti-body TAK- 888 from convalescent patients of Coronavirus. Pharmaceutical competitors of California are also seeking for similar approach to develop new drug by convalescent plasma. Moreover the American biotechnology company is also working to test whether antibodies obtained from patients of former SARS outbreak in 2003 can viable to neutralize SARS-CoV-2 [34].

\section{CONCLUSION}

A retrospective meta-analysis study showed that convalescent plasma has been an effective therapy to reduce mortality by other coronaviruses of Coronovidea family. The study showed that in case of COVID-19, this therapy also showed effective results without any lethal side-effect. Our review supports the use of convalescent plasma in this dire pandemic to reduce future mortalities. A number of individuals have recovered which will provide valuable resource of convalescent plasma to treat future patients. So besides active immunity we must undertake passive immunity to confront this exponential spread of COVID-19. Noteworthy this treatment will be helpful for short time till effective treatments of this pandemic are found.

\section{REFERENCES}

[1] Zhu N, Zhang D, Wang W, Li X, Yang B, Song J, et al. A novel coronavirus from patients with pneumonia in China. $\mathrm{N}$ Engl J Med 2020; 382: 727-33.

[2] Ksiazek TG, Erdman D, Goldsmith CS, Zaki SR, Peret T, Emery S, et al. A novel coronavirus associated with severe acute respiratory syndrome. N Engl J Med 2003; 348(20): 1953-66.

[3] Zaki AM, Van Boheemen S, Bestebroer TM, Osterhaus AD, Fouchier RA. Isolation of a novel coronavirus from a man with pneumonia in Saudi Arabia. New Eng J Med 2012; 367: 1814-20.

[4] Kraft CS, Hewlett AL, Koepsell S, Winkler AM, Kratochvil CJ, Larson L, et al. The use of TKM-100802 and convalescent plasma in 2 patients with Ebola virus disease in the United States. Clinic Infect Dis 2015; 61: 496-502.

[5] Stadler K, Masignani V, Eickmann M, Becker S, Abrignani S, Klenk HD, et al. SARS-beginning to understand a new virus. Nat Rev Microbiol 2003; 1(3): 209-18. 
[6] Wang M, Cao R, Zhang L, Yang X, Liu J, Xu M, et al. Remdesivir and chloroquine effectively inhibit the recently emerged novel coronavirus (2019-nCoV) in vitro. Cell Res 2020; 30: 269-71.

[7] Casadevall A, Pirofski LA. The convalescent sera option for containing COVID-19. J Clin Invest 2020; 130: 1545-8.

[8] Hopkins JS. Drugmaker Takeda Is Working on Coronavirus Drug. Wall Street J.2020.

[9] Perlman S, Vijay R. Middle East respiratory syndrome vaccines. Int J Infect Dis 2016; 47: 23-8.

[10] Liu Y, Li J, Feng Y. Critical care response to a hospital outbreak of the 2019-nCoV infection in Shenzhen, China. Crit Care 2020; 24: 56.

[11] Marano G, Vaglio S, Pupella S, Facco G, Catalano L, Liumbruno GM, et al. Convalescent plasma: new evidence for an old therapeutic tool?. Blood Trans 2016; 14: 152.

[12] Mair-Jenkins J, Saavedra-Campos M, Baillie JK, Cleary P, Khaw FM, Lim WS, et al. The effectiveness of convalescent plasma and hyperimmune immunoglobulin for the treatment of severe acute respiratory infections of viral etiology: a systematic review and exploratory meta-analysis. J Infect Dis 2015; 211: 80-90.

[13] Graham BS, Ambrosino DM. History of passive antibody administration for prevention and treatment of infectious diseases. Curr Opinion HIV AIDS 2015; 10: 129.

[14] Shen, C, Wang Z, Zhao F, Yang Y, Li J, Yuan J, et al. Treatment of 5 critically Ill patients with COVID-19 with convalescent plasma. JAMA 2020; 323: 1582-89.

[15] Roback JD, Guarner J. Convalescent plasma to treat COVID-19: possibilities and challenges. JAMA 2020.

[16] Park WH. Therapeutic use of antipoliomyelitis serum in preparalytic cases of poliomyelitis. J Amer Med Assoc 1932; 99: 1050-3.

[17] Rambar AC. Mumps: use of convalescent serum in the treatment and prophylaxis of orchitis. Amer J Dis Child 1946; 71: 1-13.

[18] Gallagher JR. Use of convalescent measles serum to control measles in a preparatory school. Amer J Public Health Nations Health 1935; 25: 595-8.

[19] Luke TC, Casadevall A, Watowich SJ, Hoffman SL, Beigel JH, Burgess TH. Hark back: passive immunotherapy for influenza and other serious infections. Crit care med 2010; 38: e66-73.

[20] Luke TC, Kilbane EM, Jackson, JL, Hoffman SL. Meta-analysis: convalescent blood products for Spanish influenza pneumonia: a future H5N1 treatment? Ann Inter Med 2006; 145: 599-609.
[21] Hung IF, To KK, Lee CK, Lee KL, Chan K, Yan WW, et al. Convalescent plasma treatment reduced mortality in patients with severe pandemic influenza A (H1N1) 2009 virus infection. Clinic Infect Dis 2011; 52: 447-56.

[22] Sahr F, Ansumana R, Massaquoi TA, Idriss B R, Sesay FR, Lamin $\mathrm{JM}$, et al. Evaluation of convalescent whole blood for treating Ebola Virus Disease in Freetown, Sierra Leone. J Infect 2017; 74: 302-9.

[23] Mire CE, Geisbert JB, Agans KN, Thi EP, Lee AC, Fenton, KA, et al. Passive immunotherapy: assessment of convalescent serum against Ebola virus Makona infection in nonhuman primates. J Infect Dis 2016; 214(Suppl. 3): S367-74.

[24] De Greve H, Virdi V, Bakshi S, Depicker A. Simplified monomeric VHH-Fc antibodies provide new opportunities for passive immunization. Curr Opin Biotechnol 2020; 61: 96-101.

[25] Kruse RL. Therapeutic strategies in an outbreak scenario to treat the novel coronavirus originating in Wuhan, China. F1000 Res 2020; 9: 72.

[26] World Health Organization. Coronavirus disease (COVID-19). Situation report 104. 3 May 2020.

[27] Ye M, Fu D, Ren Y, Wang F, Wang D, Zhang F, et al. Treatment with convalescent plasma for COVID-19 patients in Wuhan, China. J Med Virol 2020.

[28] China seeks plasma from recovered patients to treat virus|time. Available from: https://time.com/5784286/covid-19-chinaplasma-treatment/.

[29] Passive immunisation' can save COVID-19 patients: Pakistan's top hematologist | Tribune. Available at https:/tribune.com. pksstory.

[30] Tanne JH. Covid-19: FDA approves use of convalescent plasma to treat critically ill patients. BMJ 2020; 368: m1256.

[31] Haseltine WA. Why Researchers are exploring antibodies from recovered patients for possible treatment and prevention of COVID-19. Forbes Magazine 2020.

[32] Sheehy A. Antibodies in the blood of COVID-19 survivors know how to beat coronavirus - and researchers are already testing new treatments that harness them. The Conversation US 2020.

[33] European commission directorate-general for health and food safety. An EU programme of COVID-19 convalescent plasma collection and transfusion 2020.

[34] Freund A. Coronavirus drugs: Can antibodies from survivors help? Deutsche Welle 2020. 